\title{
Ulnar impaksiyon sendromu
}

\section{Ulnar impaction syndrome}

\author{
Mehmet Ali Acar ${ }^{1}$, Ebubekir Eravşar ${ }^{1}$, Ali Özdemir ${ }^{2}$ \\ 1Selçuk Üniversitesi Tıp Fakültesi Hastanesi, Ortopedi ve Travmatoloji Ana Bilim Dalı, Konya \\ ${ }^{2}$ Gazi Yaşargil Eğitim ve Araştırma Hastanesi, El Cerrahisi Departmanı, Diyarbakır
}

\begin{abstract}
Ulnar impaksiyon sendromu ulnar taraflı el bilek ağrısının sık görülen sebeplerinden birisidir. Ulna başının karpal kemikler ve arada bulunan triangular fibrokartilaj kompleks yapısı ile sıkışmasına bağlı olarak gelişen bir patolojidir. Bu sıkışıklığa en çok sebep olan durum pozitif ulnar varyansın varlığıdır. Ulnar deviasyon, pronasyon ve kavrama hareketleri ulnar varyansı ve dolayısıyla da impaksiyonu artırarak semptomları alevlendirmektedir. Ulnar varyans hareketlerle değişen bir durum olduğu için direkt grafi ile görüntülemenin nötral el bileği pozisyonunda yapılması önem arz etmektedir. Manyetik rezonans görüntülemede impaksiyonun olduğu eklem yüzlerinde kıkırdak dejenerasyonu ve kemik iliği ödemi gözlenmektedir. Ulnar impaksiyon sendromunda lunatumdaki ödem Kienböck hastalığındaki gibi difüz bir dağılım paterni göstermeyip, ulnaya komşuluk gösteren eklem yüzündedir. Konservatif yöntemler ulnar impaksiyon sendromunda ilk uygulanması gereken tedavi metodudur. Cerrahi tedavi ise klinik ve radyolojik olarak ulnar impaksiyon sendromu tanısı konulmuş, konservatif tedaviden yarar görmemiş ve distal radyoulnar eklem artrozu gelişmemiş hastalarda uygulanması gereken bir seçenektir. Ulnar kısaltma osteotomisi ve wafer rezeksiyonu en çok tercih edilen cerrahi yöntemlerdir. Bu iki cerrahi yöntemin de amacı aşırı yüklenmenin olduğu ulnokarpal eklemde dekompresyon sağlamaktır.
\end{abstract}

Anahtar sözcükler: ulnar impaksiyon; ulnar varyans; ulnar kısaltma; el bileği artroskopisi; wafer rezeksiyonu

\begin{abstract}
Ulnar impaction syndrome is one of the common causes of ulnar sided wrist pain. It is a pathology developing due to the compression of the ulnar head with the carpal bones and the triangular fibrocartilage complex structure. The most common cause of this compression is the presence of positive ulnar variance. Ulnar deviation, pronation and grasping movements increase the ulnar variance and impaction, and consequently the symptoms are exacerbated. Since ulnar variance is a condition that changes with movements, it is important to do the imaging with radiography in the neutral wrist position. With the help of magnetic resonance imaging, cartilage degeneration and bone marrow edema are observed in the joint surfaces where impaction is present. In ulnar impaction syndrome, the edema in the lunate bone does not show a diffused distribution pattern as in Kienböck's disease, but is on the joint surface adjacent to the ulna. Conservative methods are the initial treatments to be conducted in ulnar impaction syndrome. Surgical treatment is an option that should be applied in patients who have clinically and radiologically diagnosed with ulnar impaction syndrome, who did not benefit from conservative treatment and develop distal radioulnar joint arthrosis. Ulnar shortening osteotomy and wafer resection are the most preferred surgical methods. The purpose of these two surgical methods is to provide decompression in the ulnocarpal joint where there is overload.
\end{abstract}

Key words: ulnar impaction; ulnar variance; ulnar shortening; wrist arthroscopy; wafer resection
U Inokarpal abutment sendromu olarak da adlandırılan ulnar impaksiyon sendromu, ulnar taraflı el bilek ağrısına sebep olabilen durumlardan birisidir. Bu patolojinin gelişiminde ulna başının karpal kemiklerle oluşturduğu eklem aralığındaki daralma ve bu eklemdeki aşırı yüklenme sorumlu tutulmaktadır. Ulnar impaksiyon sendromu, kendisine isim olarak benzeyen "ulnar stiloid impaksiyon sendromu" ve "ulnar sıkışma (impingement) sendromu" ile karıştırılmaması gereken bir patolojidir. Bu diğer iki patolojinin gelişiminde tamamen farklı mekanizmalar rol almaktadır. Ulnar stiloid impaksiyon sendromu, ulnanın stiloid çıkıntısıyla trikuetrumun proksimali arasındaki daralmaya bağlı olarak gelişir. Ulnar impingement sendromunda ise sorunun sebebi, kısalmış ulnanın distal radyoulnar eklem proksimalinde sıkışmasıdır. ${ }^{[1]}$ Ulnar impaksiyon sendromunda ulnokarpal eklemdeki sıkışıklığa bağlı olarak triangular fibrokartilaj

- İletişim adresi: Prof. Dr. Mehmet Ali Acar, Akademi Mahallesi, Yeni İstanbul Caddesi, Selçuk Üniversitesi Alaeddin Keykubat Yerleşkesi, Selçuklu, Konya Tel: 0555 - 4437339 e-posta: dr.mali46@hotmail.com

- Geliş tarihi: 10 Mayıs $2021 \quad$ Kabul tarihi: 31 Mayıs 2021

ORCID iD: Mehmet Ali Acar, 0000-0003-2701-4923 • Ebubekir Eravşar, 0000-0003-2940-604X • Ali Özdemir, 0000-0002-8835-9741 


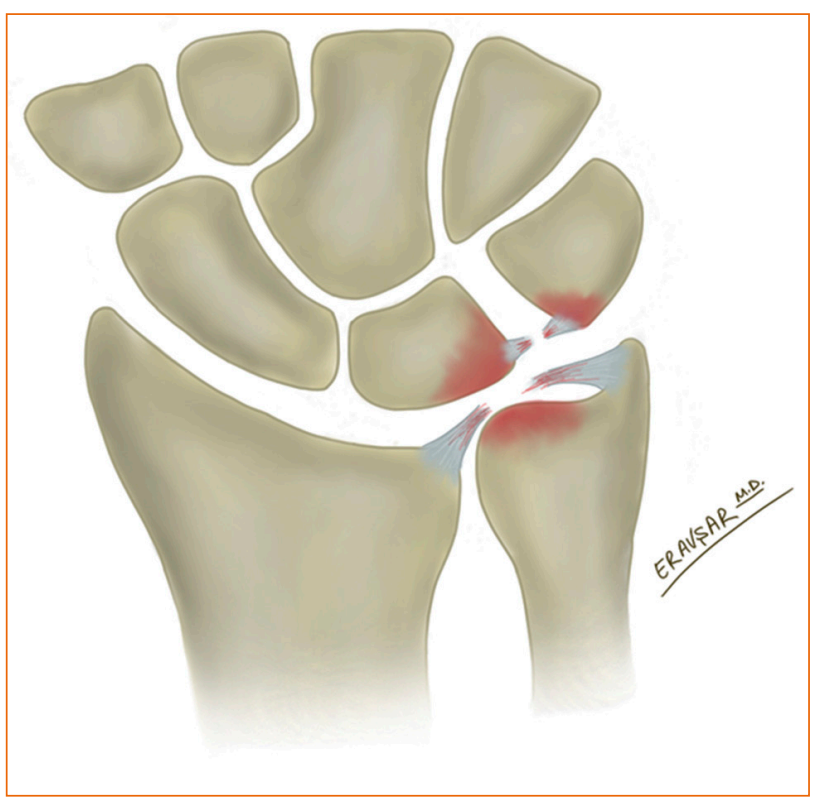

Şekil 1. Ulnar impaksiyon sendromununun klasik patogenezinin illüstrasyon üzerinde gösterilmesi. Pozitif ulnar varyansa bağlı olarak ulnokarpal sıkışma meydana gelmektedir. Bu sıkışma nedeniyle triangular fibrokartilaj kompleks (TFKK) yapısı hasarlanabilir, hatta perfore bile olabilir. Ulna, lunatum ve trikuetrumda artan yüklenmeye bağlı olarak dejenerasyon ve lunotrikuetral (LT) bağda rüptür meydana gelebilir.

kompleks (TFKK), ulna başı, lunatum, trikuetrum ve lunotrikuetral (LT) bağda da ilerleyici düzeyde eşlik eden patolojiler saptanabilmektedir (Şekil 1).

\section{ULNAR VARYANS}

Ulnar impaksiyon sendromunun gelişiminde pozitif ulnar varyans en çok suçlanan durumdur. Ulnar varyans; el bileğinde radius ve ulnanın karpal kemiklere bakan eklem yüzeylerinin birbirlerine göre pozisyonlarını tanımlayan bir terimdir. Nötral rotasyonda çekilen el bilek arka-ön radyografisine göre ölçümü yapılmaktadır. Buna göre pozitif ulnar varyansta ulna eklem yüzeyi daha distalde bulunurken, negatif ulnar varyansta ulnanın eklem yüzeyi daha proksimaldedir. İnsanlarda ortalama olarak $-0,9 \mathrm{~mm}$ olarak bulunmuştur. ${ }^{[2]}$ Nötral ulnar varyans durumunda ulna başı el bileği aksiyel yüklenmesinin \%18'ini absorbe eder. Ulnar varyans $2,5 \mathrm{~mm}$ arttığında bu yüklenme \%42'ye kadar çıkarken, 2,5 mm azaldığında ise \%4,3'e kadar azalmaktadır. ${ }^{[3]}$ Ulnar varyansın pozisyona bağlı değişken yapısı akılda tutulması gereken önemli bir durumdur. Nitekim, ön kol pronasyonu ile ulnar varyans artmakta, supinasyon ile ise azalmaktadır. Ayrıca elin kavrama hareketiyle (grip) de ulnar varyansın arttığı rahatlıkla gözlenebilmektedir. ${ }^{[4]}$

\section{Etiyoloji ve Klinik}

Ulnar impaksiyon sendromu; konjenital olarak ulnar pozitif varyanslı hastalarda görülebileceği gibi ulnar varyansın sonradan pozitifleştiği distal radius-ön kol ve radius başı yanlış kaynamalarında, distal radiusun büyüme plağının etkilendiği durumlar ve Madelung deformitesi gibi durumlarda da gelişebilmektedir. ${ }^{[3]}$

Ulnar taraflı el bileği ağrısı, aktiviteyle artan şişlik, hareket kısıtlılığı, güç kaybı ve el bileğinden klik şeklinde gelen ses sık görülen yakınmalardandır. Ulnokarpal stres testi ağrıları provoke edebilir. Ağrı özellikle pronasyon ve ulnar deviasyon gibi ulnokarpal eklem aralığını daraltan durumlarda şiddetlenmektedir. Ulnar taraflı ağrıya sebep olabilen kırık, Kienböck hastalığı, izole TFKK yaralanması, izole LT bağ yaralanması, ulnar hammer sendromu, ulnar sinir tuzak nöropatisi, ekstansör karpi ulnaris (EKU) ve fleksör karpi ulnaris (FKU) tendiniti gibi hastalıklardan ayırt edilmesi oldukça önemlidir. ${ }^{[5]}$ Bunun için ayrıntılı hasta öyküsü, sistematik muayene ve görüntüleme tetkiklerinden yararlanılması gerekmektedir.

\section{Görüntüleme}

Görüntülemede pozitif ulnar varyans genellikle dikkati çeken ilk bulgudur (Şekil 2). Ancak nötral ulnar varyans ve negatif ulnar varyans durumlarında da ulnar impaksiyon sendromunun gözlenebileceği unutulmamalıdır. ${ }^{[6,7]}$ Ulnar varyans pozisyona bağlı olarak değişebildiği için arka ön direkt grafi ile görüntüleme yapılırken omuza $90^{\circ}$ abduksiyon, dirseğe $90^{\circ}$ fleksiyon ve ön kola nötral pozisyon verilmesi oldukça önemlidir. Ancak impaksiyonun dinamik olma ihtimaline yönelik olarak kavrama anında ve farklı pozisyonlarda da görüntülemeler yapmak tedavi aşamasında dikkat edilmesi gereken bir durumdur. ${ }^{[4]}$ Direkt grafide diğer dikkati çeken bulgular; ulna, lunat ve trikuetrum eklem yüzlerindeki skleroz ve subkondral kistik değişikliklerdir. Radyografinin yetersiz kaldığı durumlarda manyetik rezonans (MR) görüntüleme oldukça yararlıdır. Fokal kartilaj defektleri ve kemik iliği ödemi dikkat çekici bulgulardır. Kemik iliği ödemine bağlı sinyal artışı özellikle lunatumun ulnar eklem yüzünde gözlenmektedir (Şekil 2). Ödem trikuetrumun ve ulnanın radyal tarafında da izlenebilir. Kienböck hastalığında MR görüntüleme bulguları her ne kadar ulnar impaksiyon sendromunu taklit edebilse de ayırt edici birkaç nokta vardır. Kienböck hastalığında ödem daha difüz seyreder, ayrıca trikuetrum ve ulna başı etkilenmemiştir. [8] Ulnar impaksiyon sendromunda ise lunatumdaki ödem difüz bir dağılım paterni göstermeyip ulnaya komşuluk gösteren eklem yüzündedir. Ayrıca ulnar 

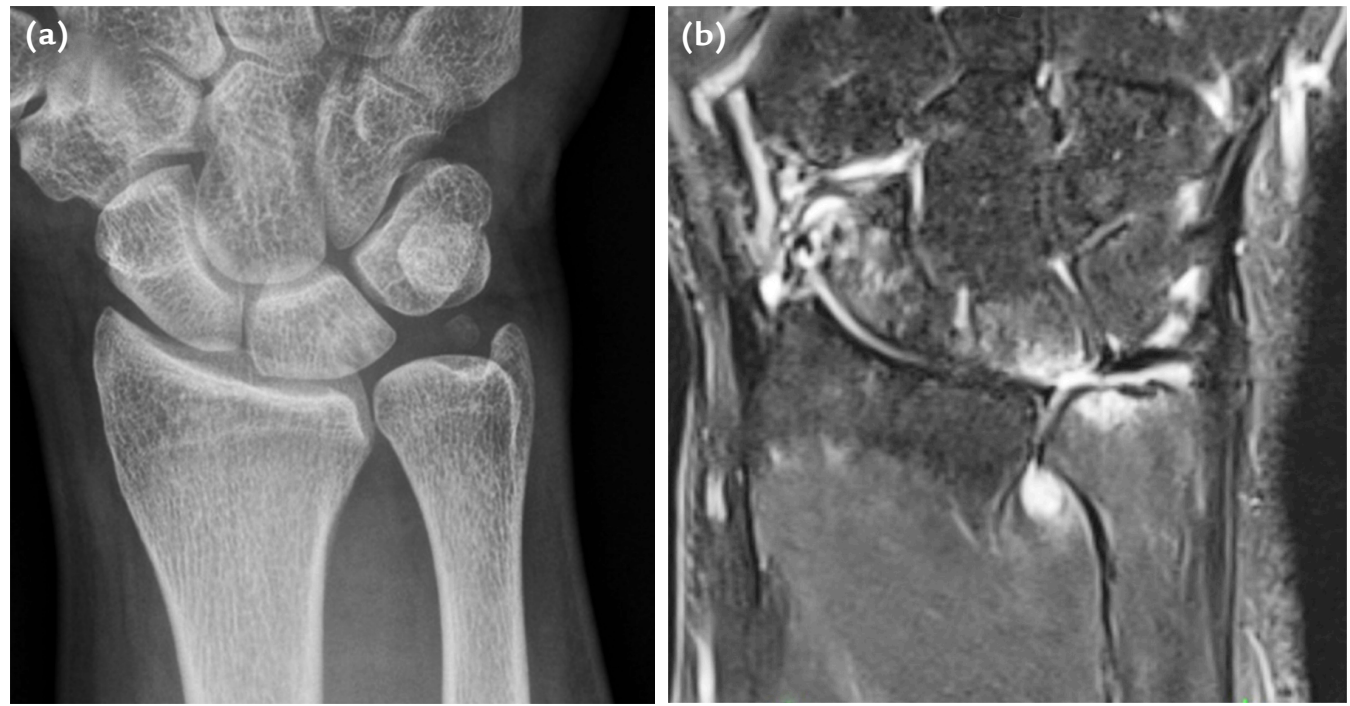

Şekil 2. a, b. Direkt radyografide lunatumda gözlenen skleroz ve subkondral kistik değiş̧iklikler ve pozitif ulnar varyans (a). Manyetik rezonans (MR) görüntülemede gözlenen lunatum ve ulnada ödem, triangular fibrokartilaj komplekste (TFKK'da) dejeneratif yırtık. Lunatumdaki ödemin özellikle ulnaya bakan yüzeyde olduğuna dikkat edilmelidir (b).

impaksiyonlu hastalarda genellikle pozitif ulnar varyans gözlenirken, Kienböck hastalarında negatif ulnar varyans dikkat çekmektedir. Ancak bu noktada ulnar varyansın MR ile ölçülmesinin yanlış sonuçlar verebileceği unutulmamalıdır. Çünkü MR çekilirken hastanın koluna verilen pozisyon ulnar varyansı değiştirebilir ve yanlış ölçümlere sebep olabilir. ${ }^{[9]}$ Bir başka yardımcı görüntüleme tekniği MR artrografidir. MR artrografiyle ulnar impaksiyon sendromuna eşlik eden TFKK ve LT bağ yaralanmaları daha ayrıntılı incelenebilmektedir. Ulna başının lunatum ve trikuetruma kronik yüklenmesi; hem arada bulunan TFKK yapısının incelip yaralanmasına hem de LT instabilitelerine neden olabilir. ${ }^{[4,9]}$

\section{ULNAR IMPAKSIYON SENDROMU VE TFKK YARALANMASI}

Ulnar impaksiyon sendromu ve TFKK yaralanması birlikteliğinin varlığı eskiden beri bilinmektedir. TFKK yaralanmalarını sistematik olarak sınıflayan Palmer dejeneratif yani Tip 2 sınıfındaki yaralanmaları ulnar impaksiyon sendromuyla ilişkilendirmiştir (Tablo 1). ${ }^{[9,10]}$ TFKK'nin santral diski karpal kemikler ile ulna başı arasındaki yük transferini sağlayan yapıdır. Bu diskin dejenerasyonu sonucu oluşan santral defektlerde eklem kıkırdaklarının dejenerasyonuna kadar giden bir süreç gelişebilmektedir. ${ }^{[11]}$ Dejenerasyona uğramış TFKK yapısının komplet rüptüre olup olmamasına göre yapılacak olan cerrahi prosedür değişebilmektedir.

\section{Tedavi}

Ulnar impaksiyon sendromu öncelikle konservatif olarak tedavi edilmelidir. İmmobilizasyon, steroid olmayan anti-enflamatuvar ilaçlar, steroid enjeksiyonları ve yaşam değişiklikleri konservatif tedavinin temelini oluşturmaktadır. Cerrahi tedavi ise klinik ve radyolojik olarak ulnar impaksiyon sendromu tanısı konulmuş, konservatif tedaviden yarar görmemiş ve distal radyoulnar eklem (DRUE) artrozu gelişmemiş hastalarda

Tablo 1. Triangular fibrokartilaj kompleks (TFKK) yaralanmalarında Palmer sınıflaması ${ }^{[9,10]}$

\begin{tabular}{ll}
\hline Tip & 1: Travmatik \\
\hline 1A & Santral perforasyon \\
1B & Ulnar avülsiyon \pm ulna distalinde kırık \\
1C & Distal avülsiyon \\
1D & Radyal avülsiyon \pm sigmoid çentik kırığı \\
\hline Tip & 2: Dejeneratif \\
\hline 2A & TFKK aşınması \\
2B & TFKK aşınması + lunatum/ulna kondromalazisi \\
2C & TFKK perforasyonu + lunatum/ulna kondromalazisi \\
2D & TFKK perforasyonu + lunatum/ulna kondromalazisi + \\
& LTyırtı̆ı \\
2E & TFKK perforasyonu + lunatum/ulna kondromalazisi + \\
& LTyırtığı + ulnokarpal artroz
\end{tabular}



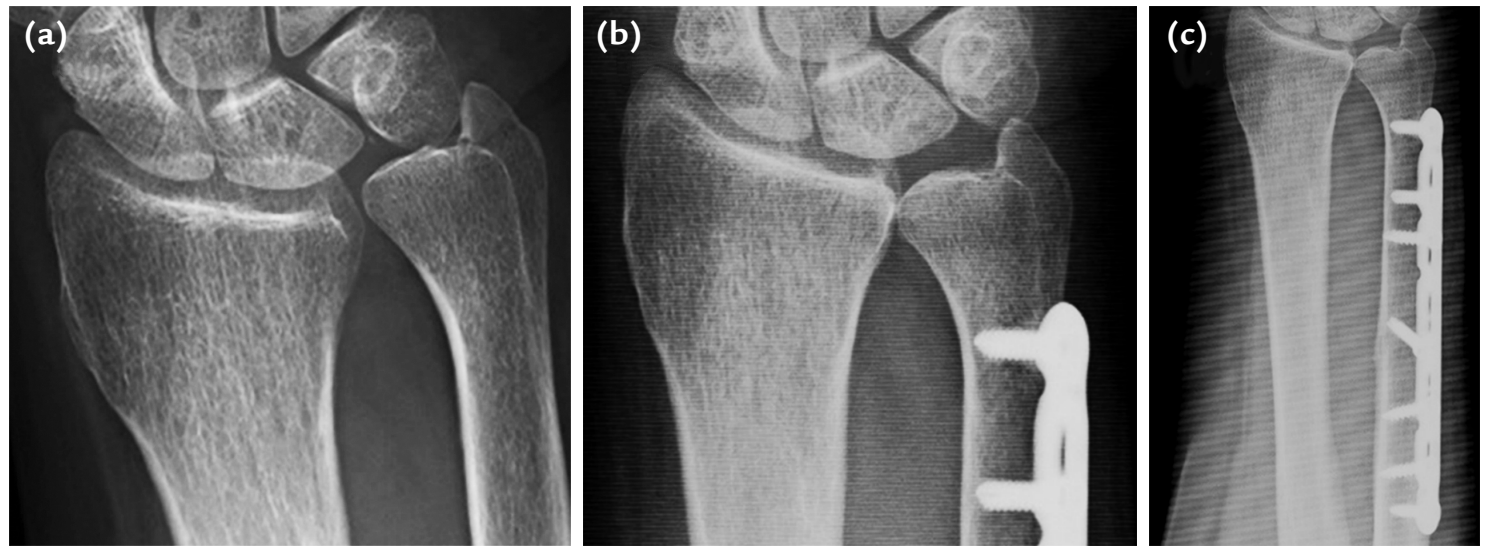

Şekil 3. a-c. Cerrahi öncesi görülen pozitif ulnar varyans (a) ulnar kısaltma osteotomisi sonrası normal seviyeye getirilmiştir (b). Ulnar kısaltma osteotomisinde plağın yerleşimi (c).

uygulanması gereken bir seçenektir. Cerrahide amaç aşırı yüklenmenin olduğu ulnokarpal eklemde dekompresyon sağlamaktır. Bunu sağlamak adına temelde ulnar kısaltma osteotomisi ve wafer rezeksiyonu olmak üzere iki cerrahi teknik tanımlanmıştır. Wafer rezeksiyonu açık veya artroskopik olarak uygulanabilmektedir. ${ }^{[1,3]}$ Yapılan çalışmalardaki konsensusa göre ameliyat sonrası elde edilmesi planlanan ulnar varyans 0 ve $-1 \mathrm{~mm}$ arasında bulunmuştur. ${ }^{[1]}$ Negatif veya nötral ulnar varyansı bulunan ulnar impaksiyon sendromlu hastalar ise artroskopik olarak TFKK, kondral yüzey ve LT bağ debridmanından yarar görebilir. ${ }^{[12]}$

\section{Ulnar Kısaltma Osteotomisi}

Ulnar kısaltma osteotomisinde eklem yüzeyine zarar verilmemesi ve istenilen ölçüde ulnar varyansın ayarlanabilmesi bu tekniğin sağladığı en önemli avantajlardır. Bu işlem, travma sonrası nedenlere bağlı olarak radyal kısalık gelişen pozitif ulnar varyanslı hastalarda DRUE eklem uyumunun tekrardan sağlanmasına ve ulnokarpal bağlardaki laksitenin azalmasına katkı sağlayabilir. Cerrahi sonrası belli bir süre immobilizasyon gerektirmesi, kaynamama ve plak irritasyonu ise başlıca dezavantajlarıdır. Kısaltma öncesi DRUE eklem uyumsuzluğu olmayan hastalarda ise ameliyat sonrası kısaltmaya bağlı olarak eklemde uyumsuzluk meydana gelebileceği göz önünde bulundurulması gereken bir durumdur. ${ }^{[13]}$ Ulnar kısaltma osteotomisi için birçok cerrahi teknik ve tespit yöntemi tanımlanmıştır.

\section{Önerilen cerrahi teknik}

Ulna boynundan proksimale doğru yapılan $10 \mathrm{~cm}$ 'lik cilt insizyonu sonrası EKU ve FKU arasından girilerek kemik dokuya ulaşılır. Ulnar sinirin dorsal duyu dalı bu yaklaşımda korunması gereken önemli bir yapıdır.
Kısaltma genellikle ulnanın orta-distal 1/3 bileşkesinden uygulanmaktadır. Osteotomi oblik veya transvers şekilde uygulanabilir. Elektrokoter ile ulna aksı boyunca longitudinal işaretleme yapılması osteotomi sonrası rotasyonun ayarlanmasına katkı sağlayacaktır. 6-7 delikli 3,5 mm'lik dinamik kompresyon plağıyla yeterli tespit sağlanabilmektedir. Osteotomi öncesi plak planlanan osteotomi hattını ortalayacak biçimde yerleştirilir. Ardından plağın en distalindeki iki vida deliğinden nötral pozisyonda vida delikleri açılarak vidalanır. Bu işlemin ardından en distaldeki vida kısmi olarak gevşetilir ve diğer vida ise tamamen çıkartılır. Böylece plak osteotomi hattı ortaya çıkacak şekilde öne veya arkaya doğru hareketlendirilebilir. Osteotomi ve uygun miktarda kısaltma uygulandıktan sonra plak tekrar yerine alınarak daha önce gevşetilmiş ve çıkartılmış olan en distal iki vida tekrar sıkılır. Kemik fragmanlar uygun pozisyonda redükte edildikten ve cerrah tarafindan aksiyel kompresyon sağlandıktan sonra osteotomi hattının proksimalindeki deliğe dinamik kompresyon sağlayacak şekilde vidalama yapılır. Ardından kalan delikler doldurularak işlem tamamlanır (Şekil 3). Osteotomi oblik uygulandığı takdirde osteotomi hattını geçecek şekilde plak üzerinden lag vidası da uygulanabilir.

Cerrahi sonrası iki hafta immobilizasyon uygulanması önerilmektedir. ${ }^{[12]}$ Ulnar kısaltma osteotomisi sonrası kaynamama \%0 ile \%8,5 arasında gözlenmektedir. Oblik osteotominin kaynamama oranını azalttığı düşünülmektedir. Ulnanın subkutan yapıda bir kemik olmasından dolayı gelişen implant irritasyonu hastaların yakındığı ciddi bir problemdir ve bazı cerrahlar rutin olarak cerrahiden 1-2 yıl sonra implantları çıkartmaktadır. Düşük profilli plaklar ve ulnaya volar yerleşimli plak uygulamaları implant irritasyonuna bağlı ikincil cerrahi gereksinimini azaltmaktadır. ${ }^{[3,14]}$ 

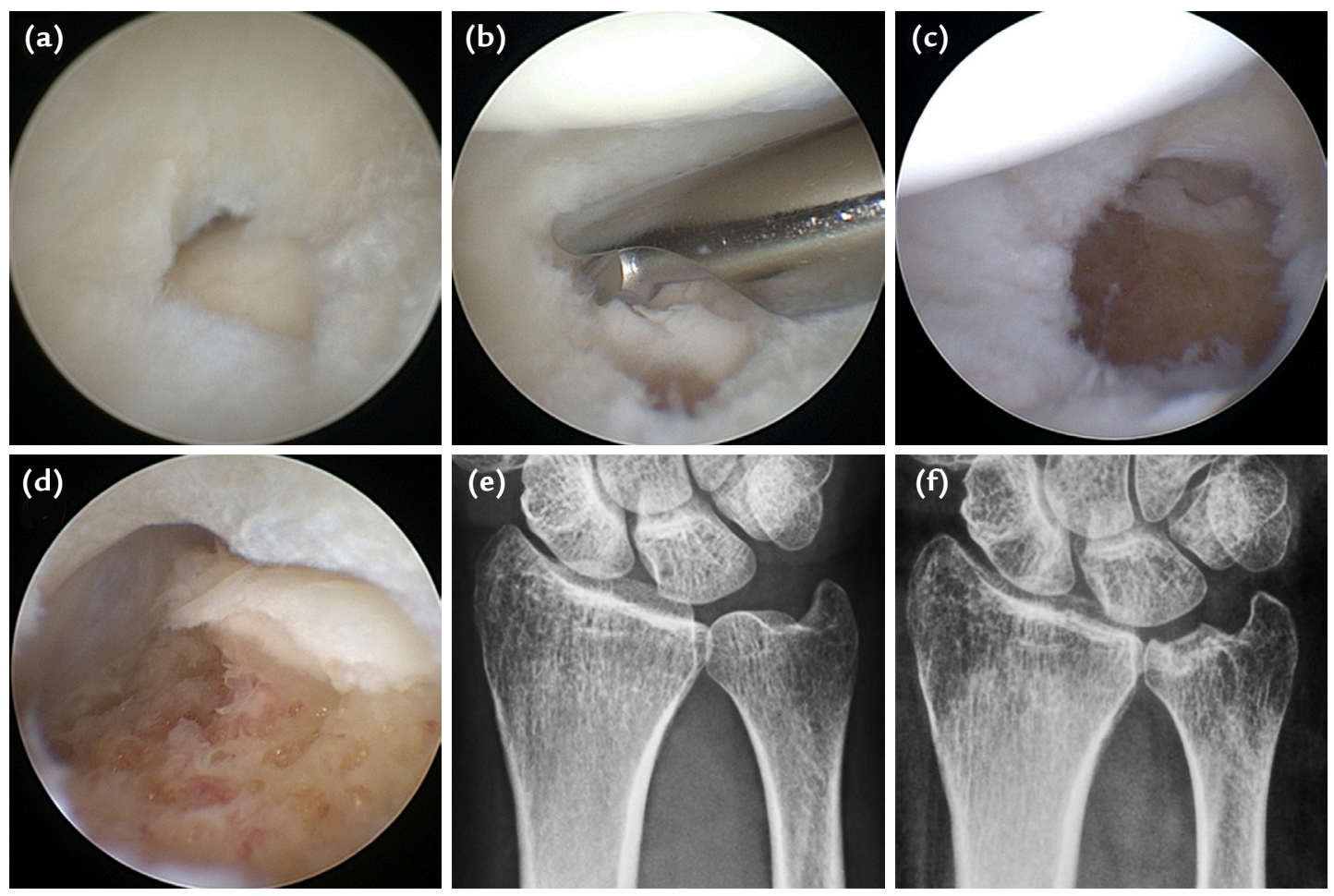

Şekil 4. a-f. Artroskopik wafer rezeksiyonunun aşamaları: Triangular fibrokartilaj kompleks (TFKK)'deki perforasyon ve TFKK'nin altında görünen ulnanın eklem yüzeyi (a). TFKK debride edildikten sonra burr yardımıyla ulnanın impaksiyona neden olan eklem yüzünün tıraşlanması (b). Debridmanı tamamlanmış TFKK ve eklem yüzeyi tıraşlanmış ulna (c). Perfore TFKK içerisinden tıraşlama bölgesine yakından bakış (d). Cerrahi öncesi (e) ve cerrahi sonrası (f) direkt grafiler.

\section{Wafer Rezeksiyonu}

Wafer prosedürü ilk olarak açık cerrahi teknikle yapılmıştır. ${ }^{[15]}$ Bu prosedürün amacı ulnanın karpal kemiklerle sıkışmaya yol açan eklem yüzünü 2-3 mm kalınlıkta ortadan kaldırmak ve böylece yüklenmeyi azaltmaktır. Herhangi bir implant kullanılmadan uygulanan bu işlemde büyük cerrahi kesilere ve kemik iyileşmesini beklemeye gerek kalmamaktadır. DRUE seviyesinden yapılan küçük bir insizyonla beşinci ekstansör kompartman üzerinden ekleme ulaşılarak uygulanabilir. Açık wafer rezeksiyonu mikro uçlu testere, osteotom veya motorize tıraşlayıcılarla yapılabilir.

Günümüzde minimal invaziv tekniklerin popülaritesinin ve uygulanabilirliğinin artmasıyla artroskopik wafer rezeksiyonu da uygulanabilmektedir. Artroskopik teknik ile eşlik eden TFKK ve LT bağ patolojilerine de müdahale edilebilmektedir. Ulnanın karpal yüklenmeye sebep olan eklem yüzünün, rüptüre TFKK (Palmer Tip 2C, 2D) içerisinden geçirilen bir burr yardımıyla 2-3 mm kalınlıkta tıraşlanması şeklinde uygulanmaktadır. Palmer Tip 2A, 2B gibi inkomplet TFKK yaralanmasının eşlik ettiği ulnar impaksiyonlu bilekler, wafer rezeksiyonu için tartışmalı konulardan birisidir. Bazı cerrahlar bu yaralanmalarda ulnar kısaltma osteotomisini önerirken, bazıları ise TFKK'da santral bir defekt oluşturarak Tip 2C ve Tip 2D'deki gibi artroskopik wafer rezeksiyonunun uygulanması gerektiğini düşünmektedir. Eşlik eden LT bağ instabiliteleri aynı seansta uygulanan 6-8 haftalık pinleme ile tedavi edilebilir. ${ }^{[9]}$

\section{Önerilen cerrahi teknik}

Traksiyondaki el bileğinin diagnostik artroskopisi tamamlandıktan sonra 2,4 mm'lik optikle 3-4 portalinden eklem içine görüntüleme için girilir. 2,5 mm'lik shaver 4-5 portalinden yerleştirilerek TFKK'daki dejenerasyon ve rüptüre defekt debride edilir. Görüntüleme için 4-5 portali, enstrümantasyon için ise $6 R$ ve $6 U$ portalleri de kullanılabilir. Debridman sonrası TFKK'daki santral defektten ulnanın eklem yüzeyi daha da görünür hale gelir. Ardından motorize $2,5 \mathrm{~mm}$ 'lik tıraşlayıcı (burr); 4-5, 6U veya $6 \mathrm{R}$ portalinden eklem içine yerleştirilerek ulnanın impaksiyona neden olan eklem yüzeyi ve subkondral kemik 2-3 mm kadar tıraşlanır (Şekil 4). Tıraşlama miktarını ölçerken tıraşlayıcı 
ucunun boyutundan yararlanılabilir. Artroskopik wafer rezeksiyonu uygulanırken el bileğine maksimum pronasyondan maksimum supinasyona kadar rotasyon uygulanması oldukça önemli bir ayrıntıdır. Böylece yeterli miktarda ulna eklem yüzünün alındığından ve impaksiyona neden olacak kemik fragman kalmadığından emin olunmuş olur. ${ }^{[16]}$ Ameliyat esnasında floroskopi yardımıyla da bu teyit edilebilir. TFKK'deki santral defekt debride edilirken aşırıya kaçmamak ve stabilite adına önemli olan volar, dorsal, radyal, ulnar bağlantı kısımlarının bütünlüğünü bozmamak gerekir.[11] TFKK'nin intakt olduğu durumlarda DRUE portalinden wafer rezeksiyonu uygulanabilir. ${ }^{[9]}$ Bu portal TFKK yapısının proksimalinde yer aldığı için santral diske zarar vermeden rezeksiyon yapmayı mümkün kılar.

Daha az invaziv olması, ameliyat sonrası ağrının daha az görülmesi ve ek değerlendirmelerin yapılabilmesi artroskopik wafer rezeksiyonunun en önemli avantajlarıdır. Kısıtlı miktarda dekompresyonun uygulanabilmesi ise bu tekniğin en önemli dezavantajıdır. Nitekim 4 mm'den daha fazla ulnar varyans olduğu durumlarda hem açık hem de artroskopik wafer işlemi kontrendikedir. Çünkü tıraşlama işlemi 4 mm'den daha fazla olduğunda DRUE'ye de zarar verilebilir. ${ }^{[9,12,15]}$ Artoskopik wafer rezeksiyonunun klinik sonuçları ulnar kısaltma osteotomisine benzer nitelikte olup daha az komplikasyon gözlendiği için önerilen cerrahi metot olarak gösterilmektedir. ${ }^{[17]}$

\section{KAYNAKLAR}

1. Stockton DJ, Pelletier ME, Pike JM. Operative treatment of ulnar impaction syndrome: a systematic review. J Hand Surg Br 2015;40(5):470-6. Crossref

2. Schuind FA, Linscheid RL, An KN, Chao EY. A normal data base of posteroanterior roentgenographic measurements of the wrist. J Bone Joint Surg Am 1992;74(9):1418-29. Crossref

3. Sachar K. Ulnar-sided wrist pain: evaluation and treatment of triangular fibrocartilage complex tears, ulnocarpal impaction syndrome, and lunotriquetral ligament tears. J Hand Surg Am 2008;33(9):1669-79. Crossref
4. Cerezal L, del Piñal F, Abascal F, García-Valtuille R, Pereda $\mathrm{T}$, Canga A. Imaging findings in ulnar-sided wrist impaction syndromes. Radiographics 2002;22(1):105-21. Crossref

5. DaSilva MF, Goodman AD, Gil JA, Akelman E. Evaluation of Ulnar-sided wrist pain. J Am Acad Orthop Surg 2017;25(8):e150-6. Crossref

6. Friedman SL, Palmer AK. The ulnar impaction syndrome. Hand Clin 1991;7(2):295-310. Crossref

7. Tomaino MM. Ulnar impaction syndrome in the ulnar negative and neutral wrist. Diagnosis and pathoanatomy. J Hand Surg Br 1998;23(6):754-7. Crossref

8. Imaeda $\mathrm{T}$, Nakamura R, Shionoya K, Makino N. Ulnar impaction syndrome: MR imaging findings. Radiology 1996;201(2):495-500. Crossref

9. Slutsky DJ. Arthroscopic management of ulnocarpal impaction syndrome and ulnar styloid impaction syndrome. Hand Clin 2017;33(4):639-50. Crossref

10. Palmer AK. Triangular fibrocartilage complex lesions: a classification. J Hand Surg Am 1989;14(4):594-606. Crossref

11. Bickel KD. Arthroscopic treatment of ulnar impaction syndrome. J Hand Surg Am 2008;33(8):1420-3. Crossref

12. Adams BD, Leversedge FJ. Distal radioulnar joint. In: Wolfe SW, Pederson WC, Kozin SH, Cohen MS, editors. Green's Operative Hand Surgery, 2-Volume Set, 7th ed. Philadelphia: Elsevier/Churchill Livingstone; 2016. p.479-515.

13. Feldon P, Terrono AL, Belsky MR. Wafer distal ulna resection for triangular fibrocartilage tears and/or ulna impaction syndrome. J Hand Surg Am 1992;17(4):731-7. Crossref

14. Boardman MJ, Imbriglia JE. Surgical management of ulnocarpal impaction syndrome. J Hand Surg Am 2010;35(4):649-51, quiz 651. Crossref

15. Feldon P, Terrono AL, Belsky MR. The "wafer" procedure. Partial distal ulnar resection. Clin Orthop Relat Res 1992;(275):124-9. Crossref

16. Loftus JB. Arthroscopic wafer for ulnar impaction syndrome. Tech Hand Up Extrem Surg 2000;4(3):182-8. Crossref

17. Bernstein MA, Nagle DJ, Martinez A, Stogin JM, Jr., Wiedrich TA. A comparison of combined arthroscopic triangular fibrocartilage complex debridement and arthroscopic wafer distal ulna resection versus arthroscopic triangular fibrocartilage complex debridement and ulnar shortening osteotomy for ulnocarpal abutment syndrome. Arthroscopy 2004;20(4):392-401. Crossref 